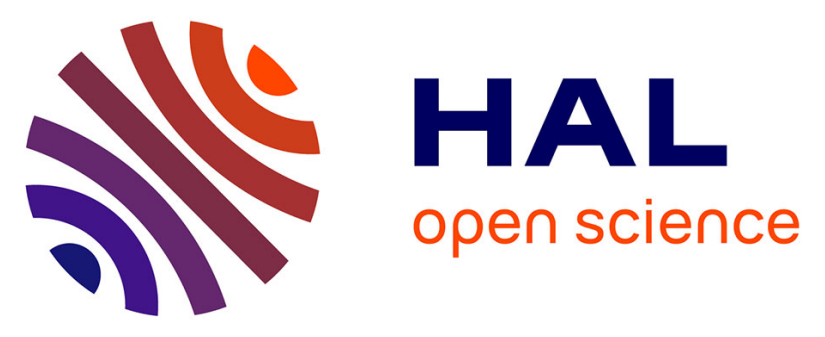

\title{
Rituximab-Induced Serum Sickness Is More Frequent in Autoimmune Diseases as Compared to Hematological Malignancies: A French Nationwide Study
}

Guillaume Bayer, Marie-Sara Agier, Bertrand Lioger, Marion Lepelley, Marie Zenut, Mary-Christine Lanoue, François Maillot, Annie-Pierre Jonville-Bera

\section{- To cite this version:}

Guillaume Bayer, Marie-Sara Agier, Bertrand Lioger, Marion Lepelley, Marie Zenut, et al.. RituximabInduced Serum Sickness Is More Frequent in Autoimmune Diseases as Compared to Hematological Malignancies: A French Nationwide Study. European Journal of Internal Medicine, 2019, 67, pp.59-64. 10.1016/j.ejim.2019.06.009 . hal-03158768

\section{HAL Id: hal-03158768 https://hal.science/hal-03158768}

Submitted on 20 Dec 2021

HAL is a multi-disciplinary open access archive for the deposit and dissemination of scientific research documents, whether they are published or not. The documents may come from teaching and research institutions in France or abroad, or from public or private research centers.
L'archive ouverte pluridisciplinaire HAL, est destinée au dépôt et à la diffusion de documents scientifiques de niveau recherche, publiés ou non, émanant des établissements d'enseignement et de recherche français ou étrangers, des laboratoires publics ou privés.

\section{(ㅇ)(1) $\$$}

Distributed under a Creative Commons Attribution - NonCommerciall 4.0 International 
Version of Record: https://www.sciencedirect.com/science/article/pii/S095362051930192X

Manuscript_d37ddfa856fd7911ae881d191d3edd86

Rituximab-induced serum sickness is more frequent in autoimmune diseases as compared to hematological malignancies: a French nationwide study.

Guillaume BAYER ${ }^{1,2}$, Marie-Sara AGIER ${ }^{3}$, Bertrand LIOGER ${ }^{1}$, Marion LEPELLEY ${ }^{4}$, Marie ZENUT $^{5}$, Mary-Christine LANOUE ${ }^{6}$, François MAILLOT ${ }^{1,2}$, Annie-Pierre JONVILLEBERA $^{3,7}$.

${ }^{1}$ CHRU de Tours, Service de médecine interne, Tours, France

${ }^{2}$ Université François Rabelais, Tours, France

${ }^{3}$ CHRU de Tours, Centre Régional de pharmacovigilance Centre Val de Loire, Tours, France

${ }^{4}$ CHRU de Grenoble, Centre Régional de pharmacovigilance, Grenoble, France

${ }^{5}$ CHRU de Clermont-Ferrand, Centre Régional de pharmacovigilance, Clermont-Ferrand, France

${ }^{6}$ CHRU de Tours, OMEDIT Centre Val de Loire, Tours, France

${ }^{7}$ Université de Tours, Université de Nantes, INSERM, SPHERE U1246, Tours, France

Corresponding author: Guillaume BAYER - Service de médecine interne, Hôpital Bretonneau - CHRU de Tours, 2 Boulevard Tonnellé, 37044 TOURS, cedex, France.

Tel: 06.11.14.63.89 ; Fax : 02.47.47.60.15 ; Email : guillaume.bayer@ hotmail.fr

The authors declare that there is no conflict of interest regarding the publication of this article.

Funding: None 
Keywords:

Rituximab; serum sickness; delayed reaction; immune complexes; adverse effect.

\section{HIGHLIGHTS:}

- We analyzed 37 cases of rituximab induced serum sickness (RISS).

- RISS occurred mainly after the first injection of rituximab.

- RISS was significantly more frequent during autoimmune diseases, especially Lupus. 


\section{Introduction}

Rituximab is a murine-human chimeric monoclonal IgG1-kappa antibody that targets the CD20 cell surface molecule. Registered in France since 1998, rituximab is approved to treat non-Hodgkin's lymphoma, chronic lymphocytic leukemia, rheumatoid arthritis (RA), granulomatosis with polyangiitis, and microscopic polyangiitis. Rituximab is also used "off label" to treat other diseases, such as immune thrombocytopenic purpura (ITP) [1], Sjögren's syndrome (SS) [2], cryoglobulinemia [3], pemphigus [4], membranous nephropathy [5], and other refractory autoimmune diseases [6].

The most common side effects described with rituximab therapy are infusion-related reactions, such as fever, chills, and shivering, which occur frequently after the first infusion and are often related to cytokines release [7]. Apart from these immediate reactions, other serious adverse drug reactions (ADR) have been reported with rituximab, including neutropenia, thrombocytopenia, hypogammaglobulinemia, bacterial and viral infections, skin reactions, as well as pulmonary, neurological, and cardiac problems [8,9]. Serum sickness, a delayed immunological reaction, have also been reported [10].

Serum sickness is a type III hypersensitivity reaction which was first described in 1905 as a complication of horse serum given as antitoxin to treat diphtheria. Later, similar cases were reported after the injection of other equine-based antitoxins or antivenins, hormones from other species, streptokinase, vaccines, antibiotics, or monoclonal antibodies prepared from animal serum $[11,12]$. The frequency of serum sickness depends on the type of antigen exposure, and ranges from $0.007 \%$ for amoxicillin to $86 \%$ for horse antithymocyte globulin $[12,13]$.

The first case of rituximab-induced serum sickness (RISS) was reported in 2001 in a patient treated for refractory autoimmune polyneuropathy [14]. More recently, a systematic review 
described 33 published cases [15] but in this study, there was no detailed assessment of the adverse reactions observed with rituximab. Thus, we conducted the present study to describe the epidemiological and clinical characteristics of RISS cases reported in France since the marketing of rituximab. More precisely, the first aim of the study was to determine the delay from rituximab infusion to RISS onset, clinical and biological features of RISS, and finally RISS outcome. The second aim of the present study was to compare both RISS characteristics and incidence according to the indication of rituximab for hematological malignancies $v s$ autoimmune diseases. We analyzed all cases reported to the French Pharmacovigilance authorities since 1998.

\section{Materials and method}

Cases of serum sickness were identified from the French Pharmacovigilance Database (FPVD) which includes every spontaneous adverse drug reaction (ADR) reported to the 31 Regional French Pharmacovigilance Centers since 1985 [13]. Briefly, every health practitioner must report ADRs to their Regional Pharmacovigilance Centre according to French law regulations [14]. All suspected ADRs reported are analyzed with a data extraction form, validated, and then registered in the FPVD, which allows an evaluation of drug-related ADRs. For each case, the causal relationship between the ADR and the drugs is evaluated. Drugs involved in the ADR are classified as "suspect" or "concomitant" according to the World Health Organization (WHO) criteria [15]. Thus, ADRs are encoded according to the Medical Dictionary for Regulatory Activities (MedDRA) classification in the FPVD.

For the present study, we collected all cases of serum sickness, recorded from 1998 (year of rituximab's marketing) to November 2, 2016 in which rituximab was involved. Serum sickness was defined as PT (preferred term, MedDRA 11.0, Medical Dictionary for 
Regulatory Activities) "serum sickness", or as PT "reaction serum sickness-like". For each case, drugs associated with the serum sickness were classified as suspect (drug with the highest chronological and semiological score) or other (drug with the lowest chronological and semiological score) to retain only cases of serum sickness for which rituximab was solely involved. To confirm the diagnosis of RISS, all selected cases were reviewed by the investigators using the clinical and biological data included in the case description.

The following information was abstracted from the medical records: patient characteristics, including age, sex, and comorbidities, disease for which rituximab was prescribed, administered dose, associated treatment, time from rituximab infusion to RISS onset, and clinical and biological presentation and outcome.

The number of cases of RISS recorded between 2011 and 2015 was divided by the total number of doses of rituximab delivered to all French healthcare institutions during the same period to approximate the incidence of RISS according to the therapeutic indication of rituximab, for each indication ("hematological malignancy" and "autoimmune disease"). This period was chosen because it was the only period for which data was available about the number of doses of rituximab delivered. The number of doses administrated was obtained through the data of reimbursement of all biopharmaceuticals to hospitals from the French hospital discharge database, called "Programme de Médicalisation des Systèmes d'Information" (PMSI). Indeed, a standard discharge summary report is generated for each hospitalization, containing information about the primary diagnosis and treatments delivered during hospitalization.

For statistical analysis, a chi-squared test was used to compare qualitative data. For each incidence, a 95\% confidence interval was calculated. 


\section{Results}

Of the 498881 reported ADRs recorded in the FPVD between 1998 and November 2, 2016, 261 were coded as serum sickness according to our MeDdra research term. Among them, 37 involved rituximab and were included in this study (Figure 1). In two cases, another concomitant medication was also suspected to have induced serum sickness with the same imputability score (cytarabine in one case and pneumococcal 23-polyvalent vaccine in the other).

Rituximab was prescribed for an autoimmune disease in 29 cases $(78.4 \%)$ and a hematological malignancy in eight $(21.6 \%)$. All indications are described in Table 1. Twentysix patients (70\%) were women and the median age was 38 years (IQR 29-53), but the sex ratio and median age were different between indications (Table 2). Fourteen patients (37.8\%) had concomitant treatment with corticosteroids. Five of the eight patients $(62.5 \%)$ treated for hematological malignancy had concomitant antineoplastic chemotherapy and four of 29 (13.8 $\%)$ treated for autoimmune disease received at least one other immunosuppressive therapy along with rituximab and corticosteroids.

Serum sickness occurred after a median dose of $700 \mathrm{mg}$ rituximab, following a single injection in most cases (54.1\%), with a median time from infusion to RISS onset of 12 days. The characteristics of the serum sickness and clinical and biological features are compared according to therapeutic indication in Table 3. The three most common clinical findings were rheumatologic symptoms, such as arthritis or arthro-myalgia in 34 patients (91.9\%), fever in $32(86.5 \%)$, and skin lesions, such as purpura, urticaria, or indeterminate erythema, in 29 (78.4\%). Cutaneous manifestations were significantly more frequent in patients treated for autoimmune disease $(\mathrm{p}=0.0276)$. When data were available, systemic inflammation was 
found in $92.3 \%$ of cases, complement consumption in $75 \%$, proteinuria in $69.2 \%$, and acute kidney injury in $46.7 \%$.

Therapy for RISS included corticosteroids for 25 patients (68\%). The median time to complete resolution, available for 21 patients, was 3.5 days (IQR 2-5.3). Re-challenge with rituximab was performed in 7 patients $(18.9 \%)$, leading to the recurrence of the symptoms in one $(14.3 \%)$. Six patients $(16.2 \%)$ also had cytokine release syndrome during the rituximab infusion. Non-optimal efficacy of rituximab was reported in 8 cases $(21.6 \%)$.

The reporting of RISS was significantly higher $(\mathrm{p}<0.5)$ for patients treated for autoimmune disease or systemic lupus erythematosus (SLE) than those treated for hematological malignancy (Table 4). Moreover, taking into account the existence of a SLE as the indication of rituximab or as a comorbidity ( $n=5$ patients), the incidence of RISS in patients with SLE was even higher $\left(121.4[39.4 ; 283.1] / 10^{5}\right.$ doses $)$.

\section{Discussion}

The present study reports 37 cases of well-documented RISS reported in France between 1998 and 2016, which is to our knowledge the largest series of RISS published so far. The most striking result for this series is that RISS occurred much more frequently (12-fold) when rituximab was prescribed to treat an autoimmune disease than a hematological malignancy. Although rituximab is not an approved treatment for patients with SLE, this pathology was the more representative autoimmune disorder in our study and furthermore seemed to be at higher risk for developing RISS (20-fold) than other autoimmune diseases.

In 2015, a systematic review identified 33 cases of RISS from 25 articles [15]. The patients were mostly women $(77 \%)$ and the mean age of presentation was 39 years, probably because 
most of the cases were associated with an auto immune condition (85\%), which is similar to our series. The actual prevalence of RISS is unknown but may be approximately $10 \%$ in autoimmune disorders. Indeed, in the five trials of rituximab to treat Sjogren's syndrome, six of the 61 patients $(9.8 \%)$ developed RISS $[6,19-21]$. In trials of rituximab for pediatric immune cytopenia, the prevalence ranged from $6 \%$ to $12.5 \%[1,23]$, and a prospective study reported $9.1 \%$ frequency of RISS in patients with hepatitis C virus-induced cryoglobulinemic vasculitis [24]. Patients with some autoimmune diseases may be at higher risk of RISS than others. Although systemic lupus erythematosus (SLE) is not a first-line indication for rituximab [25], 11 of the 28 patients (39\%) treated for autoimmune disease had SLE, which is the most highly represented disease in our series. The predisposition of patients with SLE to develop serum sickness following rituximab therapy requires further investigation.

Reporting RISS more commonly in auto immune diseases than in hematological malignancies suggests that the B-cell lysis induced by rituximab may lead to serum delivery of intracellular antigens and subsequent antigen-antibody complex formation and precipitation, especially in patients with autoimmune disorders. Indeed, these patients are characterized by elevated autoantibody production and reduced clearance of immune complexes. Rheumatoid factor and hypergammaglobulinemia have even been proposed as risk factors [24, 26, 27]. Our results support a mechanism of cytokine release syndrome as another possible risk factor [15], but only a small amount of hypergammaglobulinemia or rheumatoid factor was reported in our study.

The pathophysiological hypothesis mentioned above could also explain cases of RISS in the absence of previous rituximab administration, which is not generally the case for serum sickness. This is the second important result of our study. In our series, RISS following a single infusion accounted for $65.5 \%$ of patients with autoimmune disease. In the systematic 
review of 2015 [15], 37\% of RISS cases occurred after the first dose of rituximab as well. Thus, the absence of previous administration of rituximab should not exclude the diagnosis of serum sickness when suggestive symptoms occur.

In some cases of RISS, human anti-chimeric antibodies (HACA) directed against the murine component of rituximab has been detected $[14,28]$. Other studies reported the presence of HACA in pretreated patients [29], which could provide another explanation for the cases of RISS that occurred after the first infusion of rituximab [15]. Altered immune responses to foreign antigens may predispose patients with autoimmunity to develop HACA, but the true origin of these antibodies remains uncertain. Indeed, only $1 \%$ of the patients in first phase II trials developed antibodies to rituximab, and none developed serum sickness [30]. Moreover, HACA may have been undetectable in patients diagnosed with RISS because of the limits of the detection methods [14] or because the excessive amounts of rituximab completely consumed the HACA [15, 27]. For example, in the systematic review of Karmacharya [15], HACA was present in only 6 of 11 cases. Finally, some studies have shown that patients who develop HACA do not always present RISS in SLE [31] or in rheumatoid arthritis (RA) [32]. Thus, the presence or absence of HACA has not been found to be consistent with the development of RISS and there are no commercially available assays to measure it in clinical practice, making it difficult to adequately address this issue.

The third possibility to explain why rituximab causes serum sickness more frequently in patients treated for autoimmune conditions is that concurrent polychemotherapy used for hematological malignancies may be protective [33-35]. In our study, nearly $38 \%$ of patients with RISS in the context of hematological malignancy did not receive concomitant antineoplastic chemotherapy. Conversely, only $14 \%$ of patients with autoimmune disease had another immunosuppressive treatment (except corticosteroids). It is thus possible that the 
association of another immunosuppressive treatment (except corticosteroids), whether antineoplastic or not, reduces the risk of RISS. The effect could also vary from one molecule to another. For example, none of our 37 patients received cyclophosphamide, a treatment that is widely used to treat both lymphomas and autoimmune diseases. If corticosteroid therapy provides a protective effect, such an effect is minimal as most patients with RISS were taking corticosteroids at the time of rituximab administration, both in our series and in the systematic review of Karmacharya [15].

There may be a dose-dependent effect in RISS. Indeed, in one study, 10\% of patients who received $10 \mathrm{~mL}$ tetanus antitoxin developed serum sickness, whereas the administration of 80 $\mathrm{mL}$ produced the disease in almost all patients [36]. A dose-dependent effect concerning rituximab remains uncertain. In onco-hematology, rituximab is administrated at a dose of 375 $\mathrm{mg} / \mathrm{m}^{2}$ per injection, and in rheumatology, it is historically prescribed at a dose of one gram per injection, hence slightly more than in onco-hematology. However, most autoimmune diseases are treated with a dose of $375 \mathrm{mg} / \mathrm{m}^{2}$, except for RA. Among our patients, $34.5 \%$ treated for an autoimmune disease received $1 \mathrm{~g}$ rituximab, whereas only $5 \%$ were treated for RA. It is possible that this dose was over-represented among our patients, which would support the hypothesis of a dose-dependent effect.

Serum sickness usually resolves within days and can be managed with anti-histamine or corticosteroid treatment [33], but occasional reports showed substantial mortality resulting from progressive glomerulonephritis or severe neurological complications [11]. No RISS led to death in our study, but $14 \%$ of our patients experienced hemodynamic failure.

Corticosteroid therapy did not seem to accelerate recovery, perhaps because some cases quickly resolved spontaneously. Some authors have suggested the use of plasmapheresis in cases with severe manifestations [37], but the benefits of any treatment are difficult to assess 
without a placebo arm, especially because the natural history of serum sickness is to resolve spontaneously. A desensitization protocol has also been proposed [38] and authors even reported cases without recurrence after the second infusion of rituximab [15, 34]. In our study, there was a single recurrence in seven re-challenges (14.3\%). However, recurrence is certainly more frequent, because retrospective analysis of clinical data finds a probable history of RISS in more than $14 \%$ of the patients. This testifies to the difficulty of diagnosing RISS from the first episode. This was already noticed in a blinded review of potential cases of serum sickness in children after antibiotic exposure, which reported that $75 \%$ of cases were not correctly identified by the patient's physician [13].

Finally, the fact that the efficacy of rituximab was not optimal in almost a quarter of our patients may be explained by the incomplete administration of treatment and the information bias related to the mode of data collection, but also by the neutralization of rituximab within immune complexes. Indeed, studies have described a correlation between HACA and an incomplete clinical response to rituximab [39-42].

Certain limitations must be considered in interpreting our findings. First, our study was a retrospective study, which explains why some clinical or biological data were not always available from the medical records. Second, it is not possible to exclude that the number of rituximab induced serum sickness was overvalued. Indeed, rituximab was reported to be nonoptimally effective in some patients and the complex syndrome occurring a few days after the infusion could have be an exacerbation of the autoimmune disease instead of serum sickness. However, clinicians are accustomed to these exacerbations and since all cases were obtained from spontaneous notification (not from a systematic registry), it is probable that this differential diagnose was excluded before they declared the case, especially when the evolution was quickly favorable. Third, the number of RISS could be underestimated. Indeed, 
this complication without pathognomonic sign and with fast healing is poorly known, and therefore probably underdiagnosed. In addition, under-notification is a general limitation of spontaneous reporting systems for all ADR, even though notification of severe ADR is mandatory in France. The absence of underreporting would have led to greater accuracy of the estimated incidence of RISS according to indication (with lower confidence interval widths). Nevertheless, even if the true incidence is higher, we estimate that this bias was probably similar for both major groups of indications (autoimmune diseases vs hematological malignancies), which makes the comparison between groups possible. Finally, the main objective of this study was to compare the characteristics of RISS according to therapeutic indication, which does not require that all cases be collected.

\section{Conclusion}

RISS is a delayed hypersensitivity reaction due to tissue deposition of immune complexes following the administration of rituximab. The present study included 37 cases of RISS, which is the largest series published so far. The clinical signs most frequently found were rheumatologic manifestations, fever, and, especially in case of autoimmune disease, skin lesions. RISS generally arised after the first or second rituximab infusion and resolved rapidly without any obvious benefit from corticosteroid therapy. In this study, RISS was at least 12 times more frequent when rituximab was used to treat an autoimmune disease than a hematological malignancy, confirming that this reaction preferentially occurs in cases of autoimmune conditions, especially during SLE (20-fold). Although rarely severe, the recurrence of RISS and its frequent association with other side effects should prompt clinicians to question the use of rituximab after an episode of serum sickness. 


\section{References}

[1] Bennett CM, Rogers ZR, Bussel JB, et al. Prospective phase 1/2 study of rituximab in childhood and adolescent chronic immune thrombocytopenic purpura. Blood 2006;107:263942.

[2] Meijer JM, Vissink A, et al. Effectiveness of rituximab treatment in primary Sjögren's syndrome: a randomized, double-blind, placebo-controlled trial. Arthritis Rheum 2010;62:960-8.

[3] Zaja F, De Vita S, Mazzaro C, et al. Efficacy and safety of rituximab in type II mixed cryoglobulinemia. Blood 2003;101:3827-34.

[4] Joly P, Mouquet H, Roujeau JC, D'Incan M, Gilbert D, Jacquot S, et al. A single cycle of rituximab for the treatment of severe pemphigus. N Engl J Med. 2007;357:545-52.

[5] Dahan K, Debiec H, Rousseau A, et al. Rituximab for Severe Membranous Nephropathy: A 6-Month Trial with Extended Follow-Up. J Am Soc Nephrol 2017;28:348-358.

[6] Gottenberg J-E, Guillevin L, Lambotte O, et al. Tolerance and short term efficacy of rituximab in 43 patients with systemic autoimmune diseases. Ann Rheum Dis 2005;64:91320.

[7] Winkler U, Jensen M, Manzke H, et al. Cytokine-release syndrome in patients with B-cell chronic lymphocytic leukemia and high lymphocyte counts after treatment with an anti-CD20 monoclonal antibody (rituximab, IDEC-C2B8). Blood 1999;94:2217-2224.

[8] Cheungpasitporn W, Kopecky SL, Specks U, Bharucha, et al. Non-ischemic cardiomyopathy after rituximab treatment for membranous nephropathy. J Renal Inj Prev 2017;6:18-25. 
[9] Kimby E. Tolerability and safety of rituximab (MabThera). Cancer Treat Rev 2005;31:456-473.

[10] Succaria F, Sahni D, Wolpowitz D. Rituximab-Induced Serum Sickness-Like Reaction: A Histopathologic Viewpoint. Am J Dermatopathol 2016;38:321-322.

[11] Frank MM, Hester CG. Immune Complex-Mediated Diseases. Adkinson NF Jr, Bochner BS, Burks W, et al. Eds. Middleton's Allergy Principles and Practice. 8th ed. Philadelphia PA: Saunders; 2014. 602-16.

[12] Lawley TJ, Bielory L, Gascon P, Yancey KB, Young NS, Frank MM. A prospective clinical and immunologic analysis of patients with serum sickness. N Engl J Med $1984 ; 311: 1407-13$.

[13] Heckbert SR, Stryker WS, et al. Serum sickness in children after antibiotic exposure: estimates of occurrence and morbidity in a health maintenance organization population. Am J Epidemiol 1990;132:336-42.

[14] D'Arcy CA, Mannik M. Serum sickness secondary to treatment with the murine-human chimeric antibody IDEC-C2B8 (rituximab). Arthritis Rheum 2001;44:1717-8.

[15] Karmacharya P, Poudel DR, Pathak R, Donato AA, Ghimire S, Giri S, et al. Rituximabinduced serum sickness: A systematic review. Semin Arthritis Rheum 2015;45:334-340.

[16] Moore N, Noblet C, Kreft-Jais C, Lagier G, et al. French pharmacovigilance database system: examples of utilization. Therapie 1995;50:557-62.

[17] Faisandier L, Fouillet A, Bringay S, et al. [Surveillance and detection of unusual events in toxicovigilance: Review of relevant methods]. Rev Epidemiol Sante Publique 2015;63:119-31. 
[18] Lindquist M, Edwards IR. The WHO Programme for International Drug Monitoring, its database, and the technical support of the Uppsala Monitoring Center. J Rheumatol 2001;28:1180-7.

[19] Seror R, Sordet C, Guillevin L, Hachulla E, Masson C, et al. Tolerance and efficacy of rituximab and changes in serum B cell biomarkers in patients with systemic complications of primary Sjögren’s syndrome. Ann Rheum Dis 2007;66:351-7.

[20] Pijpe J, van Imhoff GW, Spijkervet FK, Mansour K, et al. Rituximab treatment in patients with primary Sjögren's syndrome: an open-label phase II study. Arthritis Rheum 2005;52:2740-50.

[21] Dass S, Bowman SJ, et al. Reduction of fatigue in Sjögren syndrome with rituximab: results of a randomised, double-blind, placebo-controlled pilot study. Ann Rheum Dis 2008;67:1541-4.

[22] Devauchelle-Pensec V, Pennec Y, Morvan J, et al. Improvement of Sjögren's syndrome after two infusions of rituximab (anti-CD20). Arthritis Rheum 2007;57:310-7.

[23] Wang J, Wiley JM, Luddy R, Bussel JB, et al. Chronic immune thrombocytopenic purpura in children: assessment of rituximab treatment. J Pediatr 2005;146:217-21.

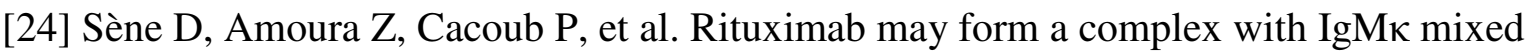
cryoglobulin and induce severe systemic reactions in patients with hepatitis $\mathrm{C}$ virus-induced vasculitis. Arthritis Rheum 2009;60:3848-55.

[25] Merrill JT, Neuwelt CM, Latinis KM, et al. Efficacy and safety of rituximab in moderately-to-severely active systemic lupus erythematosus: the randomized, double-blind, phase II/III systemic lupus erythematosus evaluation of rituximab trial. Arthritis Rheum 2010;62:222-33. 
[26] Finger E, Scheinberg M. Development of serum sickness-like symptoms after rituximab infusion in two patients with severe hypergammaglobulinemia. J Clin Rheumatol 2007;13:945.

[27] Le Guenno G, Ruivard M, Charra L, Philippe P. Rituximab-induced serum sickness in refractory immune thrombocytopenic purpura. Intern Med J 2011;41:202-5.

[28] Goto S, Goto H, Sekiguchi O, et al. Serum sickness with an elevated level of human antichimeric antibody following treatment with rituximab in a child with chronic immune thrombocytopenic purpura. Int J Hematol 2009;89:305-9.

[29] Schmidt E, Hennig K, Mengede C, Zillikens D, Kromminga A. Immunogenicity of rituximab in patients with severe pemphigus. Clinical Immunology 2009;132:334-341.

[30] Grillo-Lopez AJ, White CA, Varns C, Shen D, Wei A, McClure A, et al. Overview of the clinical development of rituximab: first monoclonal antibody approved for the treatment of lymphoma. Semin Oncol 1999;26:66-73.

[31] Looney RJ, Anolik JH, Arend LJ, et al. B cell depletion as a novel treatment for systemic lupus erythematosus: a phase I/II dose-escalation trial of rituximab. Arthritis Rheum 2004;50:2580-9.

[32] Edwards JC, SzczepanskiI L, Szechinski J, et al. Efficacy of B-Cells-targeted therapy with rituximab in patients with rheumatoid arthritis. N Engl J Med 2004;350:2572-81.

[33] Todd D, Helfgott S: Serum sickness following treatment with rituximab. J Rheumatol 2007;34:430-3.

[34] Mehsen N, Yvon CM, Richez C, Schaeverbeke T. Serum sickness following a first rituximab infusion with no recurrence after the second one. Clin Exp Rheumatol 2008;26:967. 
[35] Ungprasert P, Srivali N, et al. Rituximab-induced serum sickness in overlapping syndrome between Sjögren syndrome and systemic lupus erythematosus. J Clin Rheumatol $2013 ; 19: 360$.

[36] Erffmeyer JE. Serum sickness. Ann Allergy 1986;56:105-9.

[37] Manko A, Besecker B. Plasmapheresis Reverses ARDS in Rituximab Induced Serum Sickness. Chest 2014;146:269.

[38] Fajt ML, Petrov AA. Desensitization protocol for rituximab-induced serum sickness. Curr Drug Saf 2014;9:240-2.

[39] Albert D, Dunham J, Khan S, Stansberry J, et al. Variability in the biological response to anti-CD20 B cell depletion in systemic lupus erythaematosus. Ann Rheum Dis. 2008;67:1724-31.

[40] Looney RJ, Anolik JH, Felgar RE, et al. B cell depletion as a novel treatment for systemic lupus erythematosus: a phase I/II dose-escalation trial of rituximab. Arthritis Rheum. 2004;50:2580-9.

[41] Lunardon L, Payne A. Inhibitory human anti-chimeric antibodies to rituximab in a pemphigus patient. J Allergy Clin Immunol 2012;130:800-803.

[42] Schmidt E, Hennig K, Mengede C, Zillikens D, Kromminga A. Immunogenicity of rituximab in patients with severe pemphigus. Clinical Immunology 2009;132:334-341.

\section{Conflicts of interest}

None. This research did not receive any specific grant from funding agencies in the public, commercial, or not-for-profit sectors. 
French PharmacoVigilance Database cases of Adverse Drug Reaction (ADR) reported between 1998 and $2016(n=498,881)$

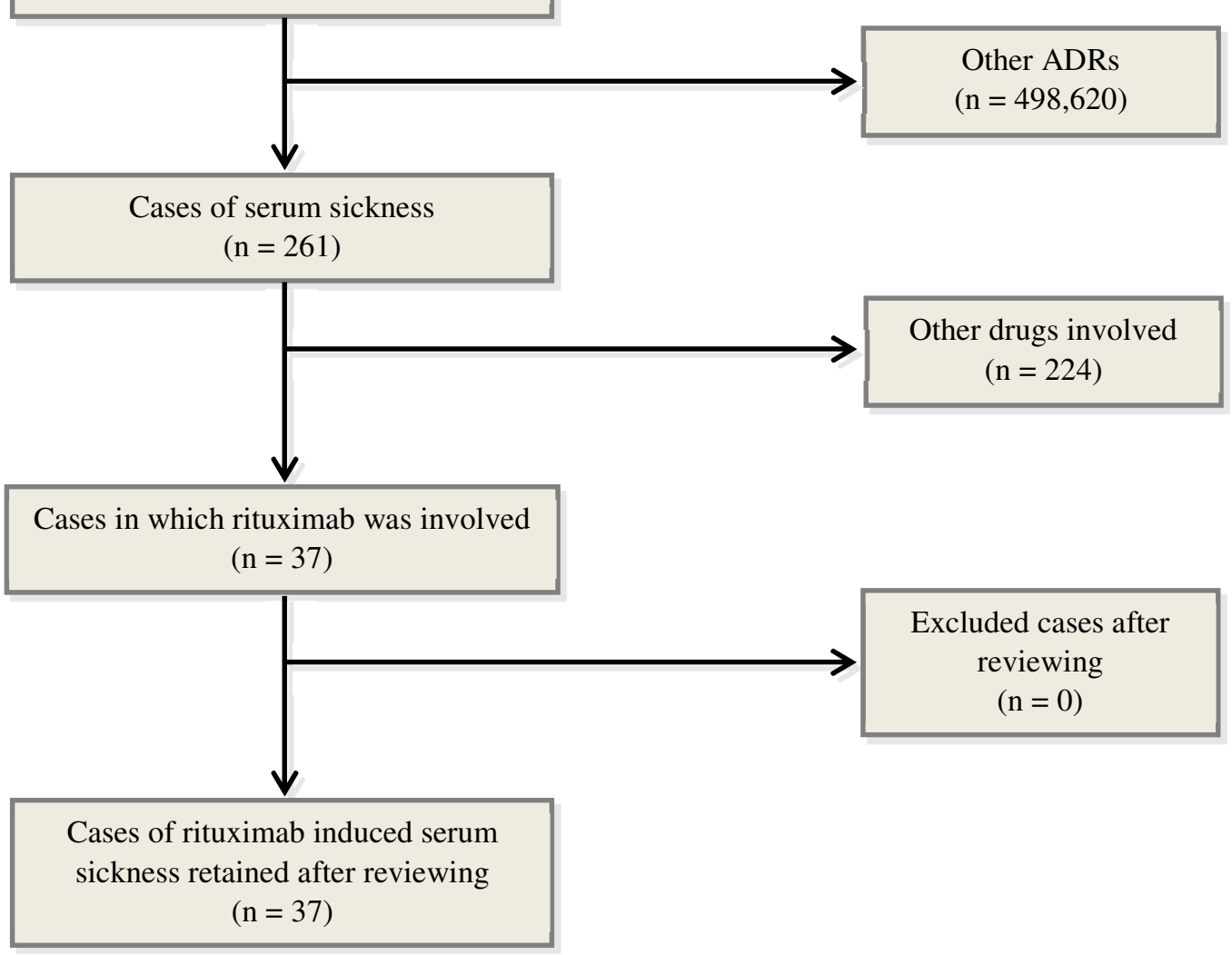

Figure 1. Study flow chart 


\begin{tabular}{lc}
\hline & Patients (\%) \\
\hline Hematological malignancy & $\mathbf{8 ( 2 1 . 6 \% )}$ \\
Follicular lymphoma & $2(25 \%)$ \\
Chronic lymphocytic leukemia & $2(25 \%)$ \\
Waldenström's macroglobulinemia & $1(12.5 \%)$ \\
Marginal zone cell lymphoma & $1(12.5 \%)$ \\
Mantle cell lymphoma & $1(12.5 \%)$ \\
EBV induced lymphoma & $1(12.5 \%)$ \\
Autoimmune disease & $\mathbf{2 9 ( 7 8 . 4 \% )}$ \\
Systemic lupus erythematosus & $8(27.6 \%)$ \\
Immunological thrombocytopenic purpura & $6(20.7 \%)$ \\
Cryoglobulinemia in Sjögren's syndrome & $3(10.3 \%)$ \\
Thrombotic thrombocytopenic purpura & $2(6.9 \%)$ \\
Rheumatoid arthritis & $2(6.9 \%)$ \\
Membranous nephropathy & $2(6.9 \%)$ \\
ANCA associated vasculitis & $1(3.4 \%)$ \\
Autoimmune hemolytic anemia & $1(3.4 \%)$ \\
Systemic juvenile idiopathic arthritis & $1(3.4 \%)$ \\
Paraneoplasic syndrome & $1(3.4 \%)$ \\
Pemphigus & $1(3.4 \%)$ \\
Interstitial lung disease & $1(3.4 \%)$ \\
\hline
\end{tabular}

Table 1. Indication for rituximab 


\begin{tabular}{|c|c|c|c|}
\hline & $\begin{array}{l}\text { Total } \\
\mathbf{N}=\mathbf{3 7}\end{array}$ & $\begin{array}{c}\text { Hematological } \\
\text { malignancy } \\
\mathbf{N}=8\end{array}$ & $\begin{array}{c}\text { Autoimmune } \\
\text { disease } \\
N=29\end{array}$ \\
\hline \multicolumn{4}{|l|}{ Characteristics of patients } \\
\hline Female gender & $26(70 \%)$ & $3(37 \%)$ & $23(82 \%)$ \\
\hline Age (median [IQR]) (years) & $38[29-53]$ & $64[52-69]$ & $35[29-46]$ \\
\hline \multicolumn{4}{|l|}{ Comorbidity } \\
\hline Other autoimmune disease (1) & $11(29.7 \%)$ & $1(12.5 \%)$ & $10(34.5 \%)$ \\
\hline Polyclonal hypergammaglobulinemia & $2(5.4 \%)$ & $1(12.5 \%)$ & $1(3.4 \%)$ \\
\hline Rheumatoid factor & $1(2.7 \%)$ & 0 & $1(3.4 \%)$ \\
\hline Hepatitis $\mathrm{C}$ virus infection & $1(2.7 \%)$ & 0 & $1(3.4 \%)$ \\
\hline \multicolumn{4}{|l|}{ Concomitant treatment } \\
\hline Hydroxychloroquine & $6(16.2 \%)$ & 0 & $6(20.7 \%)$ \\
\hline Corticosteroids & $14(37.8 \%)$ & $1(12.5 \%)$ & $13(44.8 \%)$ \\
\hline Antineoplasic (2) & $6(16.2 \%)$ & $5(62.5 \%)$ & $1(3.4 \%)$ \\
\hline Immunosuppressive (3) & $4(10.8 \%)$ & 0 & $4(13.8 \%)$ \\
\hline
\end{tabular}

Table 2. Comparison of patient characteristics according to the indication of rituximab 


\begin{tabular}{|c|c|c|c|}
\hline & $\begin{array}{l}\text { Total } \\
\mathbf{N}=37\end{array}$ & $\begin{array}{c}\text { Hematological } \\
\text { malignancy } \\
\mathbf{N}=\mathbf{8}\end{array}$ & $\begin{array}{c}\text { Autoimmune } \\
\text { disease } \\
\mathbf{N}=\mathbf{2 9}\end{array}$ \\
\hline \multicolumn{4}{|l|}{ Characteristics of serum sickness occurrence } \\
\hline Time after beginning of rituximab (median [IQR]) (days) & $12[8-15]$ & 22 [17-29] & $9[8-12]$ \\
\hline Rituximab dose before SS (median [IQR]) (mg) & $700[643-1000]$ & $692[680-758]$ & 706 [634-1000] \\
\hline "1g on days 1 and 15" dosing regimen & $10(27 \%)$ & 0 & $10(34.5 \%)$ \\
\hline Number of infusions before SS (median [IQR]) & $1[1-2]$ & $2[2-3]$ & $1[1-2]$ \\
\hline SS after a single infusion & $20(54.1 \%)$ & $1(12.5 \%)$ & $19(65.5 \%)$ \\
\hline SS after 2 infusions & $10(27 \%)$ & $4(50 \%)$ & $6(20.7 \%)$ \\
\hline SS after 3 infusions or more & $7(18.9 \%)$ & $3(37.5 \%)$ & $4(13.8 \%)$ \\
\hline Time after last infusion (median [IQR]) (days) & $6[4-8]$ & $5[2.5-6.3]$ & $7[4-8]$ \\
\hline Onset if after the first infusion & 8 [7.8-12] & 12 & $8[7.5-10.5]$ \\
\hline Onset if after the 2 nd infusion & $2.5[1-4.5]$ & $3.5[1-6.3]$ & $2.5[1.3-3]$ \\
\hline Onset if after the $3 r d$ infusion or more & $4[3.5-5.5]$ & $4[3.5-5]$ & $4.5[3.5-5.5]$ \\
\hline Rechallenge with rituximab & $7(18.9 \%)$ & $2(25 \%)$ & $5(17.2 \%)$ \\
\hline Recurrence after re-challenge & $1(14.3 \%)$ & 0 & $1(20 \%)$ \\
\hline \multicolumn{4}{|l|}{ Clinical characteristics } \\
\hline Fever & $32(86.5 \%)$ & $8(100 \%)$ & $24(82.8 \%)$ \\
\hline Polyarthralgia or arthritis & $34(91.9 \%)$ & $7(87.5 \%)$ & $27(93.1 \%)$ \\
\hline Cutaneous manifestations & $29(78.4 \%)$ & $4(50 \%)$ & $25(86.2 \%)$ \\
\hline Odynophagia, cheilitis, or conjunctivis & $7(18.9 \%)$ & $1(12.5 \%)$ & $6(20.7 \%)$ \\
\hline Digestive disorders & $7(18.9 \%)$ & 0 & $7(24.1 \%)$ \\
\hline Hypotension & $6(16.2 \%)$ & $3(37.5 \%)$ & $3(10.3 \%)$ \\
\hline Adenopathy & $3(8.1 \%)$ & $1(12.5 \%)$ & $2(6.9 \%)$ \\
\hline \multicolumn{4}{|l|}{ Biological characteristics } \\
\hline Inflammatory syndrome & $24 / 26(92.3 \%)$ & $6 / 6(100 \%)$ & $18 / 20(90 \%)$ \\
\hline Complement consumption & $12 / 16(75 \%)$ & $4 / 4(100 \%)$ & $8 / 12(66.7 \%)$ \\
\hline Proteinuria & $9 / 13(69.2 \%)$ & $3 / 4(75 \%)$ & $6 / 9(66.7 \%)$ \\
\hline Thrombocytopenia & $8 / 31(25.8 \%)$ & $4 / 8(50 \%)$ & $4 / 23(17.4 \%)$ \\
\hline \multicolumn{4}{|l|}{ Treatment of serum sickness } \\
\hline Corticosteroids & $25(68 \%)$ & $4(50 \%)$ & $21(72 \%)$ \\
\hline Time to healing (median [IQR]) (days) & $3.5[2-5.3]$ & $5[3.8-6.3]$ & $3[2-4.3]$ \\
\hline with corticosteroids & $4[3.5-5.3]$ & $5[4.5-5.5]$ & $4[2.5-4.8]$ \\
\hline without corticosteroids & $3[2-3.8]$ & $5[4-6]$ & $2.5[2-3]$ \\
\hline
\end{tabular}

Table 3. Comparison of the characteristics of serum sickness (occurrence, clinical and biological features) according to the indication of rituximab 


\begin{tabular}{lccc}
\hline & $\begin{array}{c}\text { Number of RISS } \\
\text { reported } \\
(2011-2015)\end{array}$ & $\begin{array}{c}\text { Number of doses of } \\
\text { rituximab reimbursed } \\
(2011-2015)\end{array}$ & $\begin{array}{c}\text { Incidence of RISS } \\
/ \mathbf{1 0} \text { doses }[\mathbf{9 5 \%} \text { CI }] \\
(\mathbf{2 0 1 1 - 2 0 1 5})\end{array}$ \\
\hline Hematological malignancy & 5 & 945335 & $\mathbf{0 , 5}[\mathbf{0 , 2} ; \mathbf{1 , 2}]$ \\
Autoimmune diseases* & 16 & 248719 & $\mathbf{6 . 4}[\mathbf{3 . 7} ; \mathbf{1 0 . 4}]$ \\
Systemic lupus erythematosus & 2 & 4118 & $\mathbf{4 8 . 6}[\mathbf{5 . 9} ; \mathbf{1 7 5 . 3}]$ \\
\hline
\end{tabular}

CI: confidence interval

* other than SLE

Table 4. Estimation of the French incidence of reported cases of RISS according to the indication of rituximab 